\title{
FEATURES OF THE EFFECT OF A COMPLEX HERBAL PRODUCT ON COAGULATION PROCESSES IN TOXIC HEPATITIS IN WHITE RATS
}

${ }^{1}$ Buryat State University, Ulan-Ude

${ }^{2}$ Institute of General and Experimental Biology SB RAS, Ulan-Ude

\section{E.A. Ubeeva ${ }^{1}$, S.M. Nikolaev ${ }^{1,2}$, D.N. Olennikov², I.P. Ubeeva ${ }^{1}$}

The aim of the study is to determine the hemostasis disorders in acute experimental toxic hepatitis caused by the introduction of D-Galactosamine hydrochloride in white rats and the possibility of correction with the help of the use of a new complex herbal product. The composition of the analysed phytoextract included Hypecoum erectus L. (hypecoum straight), Hedysarum dauricum (Daur sweetvetch), Glycyrhhiza uralensis Fischer (Ural licorice), Calendula officinalis (pot marigold) and Scutellaria baicalensis (Baikal skullcap). The use of phytoextract contributed to the correction of the functional state of the liver and hypocoagulation manifestations.

Key words: complex herbal medicine, experimental hepatitis, hypocoagulation, hepatoprotective effect.

Urgency. The wide spread of viral hepatitis, the increase in frequency of toxic, drug liver damage, metabolic disorders determine the need to create means with hepatoprotective properties. In determining the severity of liver disease course in the clinic, the detection of coagulation disorders is of great importance, as prothrombin and other coagulation factors are synthesized in the liver. Clotting disorders play a significant role in the pathogenesis of liver damages, are able to acquire a cascade character, lead to disseminated intravascular coagulation, microcirculation disorders, burden the course of pathological process thus determining the outcome of diseases $[1,2]$.

Medicines of plant origin attract the attention of researchers due to a wide range of pharmacotherapeutic effects, low toxicity, possibility to potentiate the effect due to the combination of various biologically active substances, especially in complex herbal products $[3,4,5]$.

The research objective was to determine the nature of changes of coagulation hemostasis in rats under the influence of a new complex herbal agent on the model of toxic hepatitis caused by the introduction of D-Galactosamine hydrochloride.

\section{Materials and methods}

The studied complex herbal product ( $\mathrm{CHP}$ ) was a combined dry extract consisting of dry extracts of hypecoum straight (Hypecoum erectum L.; Papaveraceae) herb, Alpine sweetvetch (Hedysarum alpinum L.; Leguminosae) herb, pot marigold (Calendula officinalis L.; Compositae) flowers, Ural licorice (Glycyrrhiza uralensis Fisch.; Leguminosae) roots, and Baikal skullcap (Scutellaria baicalensis Georgi; Lamiaceae) roots in the ratio of 5:5:4:4:2. Quantitative standardization of the product was carried out by HPLC-UV method using the Milichrom A-02 microcolumn liquid chromatograph (Econova, Novosibirsk, Russia).
Pharmacotherapeutic effectiveness of a CHP was determined in toxic hepatitis caused by the introduction of D-Galactosamine hydrochloride. To determine the coagulation process disorders in liver damage by D-Galactosamine hydrochloride, the methods generally accepted in hemostasiology were used and the level of fibrinogen was determined by generally accepted methods, as well as the activated partial thromboplastin time (APTT), prothrombin index (PI), prothrombin time (PT), international normalized ratio (INR), prothrombin ratio (PR) in blood serum of white rats. The condition of the coagulation link of the hemostasis system was investigated with the help of a number of tests conducted using the AO Abris and Vital standard set of reagents on the Vitarei analyzer.

According to researchers, D-Galactosamine hydrochloride causes disorders of the RNA and protein synthesis, forms acute hepatitis identical to viral human hepatitis in morphological and biochemical changes in the liver [7]. D-Galactosamine liver damage was caused by a single intraperitoneal introduction to white rats at a dose of $400 \mathrm{mg} / \mathrm{kg}$ [7]. The CHP obtained in a form of a dry extract was dissolved in purified water and administered intragastrically to three groups of white rats one hour before the introduction of hepatotoxin at doses of $100 \mathrm{mg} / \mathrm{kg}, 200 \mathrm{mg} / \mathrm{kg}, 300$ $\mathrm{mg} / \mathrm{kg}$. In the future, the dry extract continued to be administered intragastrically to groups of animals in these doses once a day for 14 days of the experiment. The comparator drug was Carsil with the international name Silibinin from the blessed milk thistle Silybum marianum (L.) Gaertn. Carsil was administered intragastrically at a dose of 100 $\mathrm{mg} / \mathrm{kg}$ in a similar mode. The control group of white rats was administered an equivalent amount of purified water in a similar mode after the introduction of D-Galactosamine hydrochloride. The intact group of animals consisted of white rats 
of the same age and sex receiving purified water in the appropriate amount under this scheme.

Experiments were conducted on 96 white rats of both sexes with an initial weight of $180 \pm 20 \mathrm{~g}$. Animal maintenance was carried out in accordance with the "Good Laboratory Practice" (GLP) and the Order of the Ministry of Health of the Russian Federation No. $708 \mathrm{H}$ dated 23.08.2010 "On Approval of Regulations of Laboratory Practice". Laboratory animals meeting the requirements for inclusion in the experiment were divided into groups according to sex, age, weight, and randomization. Experimental work was carried out in accordance with "Animal Experimentation Legislations" (Appendix to the Order of the Ministry of Health of the USSR No. 755 dated 12.08.77), "Requirements of the European Convention for the Protection of Vertebrate Animals" (Strasbourg, 1986). The report of the study was agreed with the Ethics Committee of the Buryat State University (No. 2 dated 04.12.2016).

Pharmacotherapeutic effectiveness of the studied phytoextract was determined after 7, 14 days from the beginning of the experiment. Statistical processing of the obtained data was carried out on the basis of modern packages of applied mathematical programs using the Student's t-test. The differences were considered statistically reliable at $\mathrm{p}<0.05$.

\section{Results and discussion}

With the introduction of D-Galactosamine hydrochloride, experimental animals in the early periods of the experiment did not show a sharp deterioration of their state, they maintained motor activity and appetite. The body weight of white rats in experimental groups did not change during the first week of the experiment, and in intact animals the weight increased by 20-25 g. In the second week, motor activity decreased in experimental animals, appetite worsened, body weight decreased by 10 $12 \%$ compared to intact rats.
Results showed that the formation of experimental hepatitis caused by D-Galactosamine hydrochloride was accompanied by significant hemostasis disorders (Table 1,2). On the 7th day of the experiment, the content of fibrinogen being one of the most important indicators of hemostasis was significantly reduced compared to the level in intact rats. In the control group of animals, the fibrinogen index remained reduced on the 14th day of the experiment as well, indicating the preservation of hypocoagulation. In most animals of the experimental group, against the background of the introduction of Carsil, this indicator remained reduced and differed from the control group by no more than $10 \%$. In the group of rats receiving CHP (Table 1), the level of fibrinogen increased in 6 out of 8 to $2.0 \mathrm{~g} / \mathrm{L}$ and higher.

The APTT indicator, one of the basic coagulogram indicators, depending on the concentration of plasma factors (II, V, VIII, IX, X, XI, XII, and fibrinogen), allowing to evaluate the effectiveness of the internal path coagulation reflected significant changes in the coagulation system in the group of experimental animals. On the 7 th day of the experiment, APTT increased by $8.21 \%$ in the group of animals receiving Carsil, with the introduction of the studied polyextract by $15.6 \%-18.5 \%$, reflecting a decrease in the manifestations of hypocoagulation.

Prothrombin index (PI) used in clinical conditions as an objective criterion for the severity of liver damage and coagulation disorders decreased significantly in the formation of D-Galactosamine hepatitis. With the introduction of the Carsil reference hepatoprotector, white rats revealed an increase in PI in 3 animals out of 8 , averaging 9.75\% on the 7th day of the experiment. With the use of the studied phytopolyextract, the increase in the PI in white rats amounted to $20.6-23 \%$ at doses of 100 $\mathrm{mg} / \mathrm{kg}, 200 \mathrm{mg} / \mathrm{kg}, 300 \mathrm{mg} / \mathrm{kg}$ on the $7 \mathrm{th}$ day of the experiment.

Table 1

Status of blood coagulation cascade in white rats in the case of D-Galactosamine hydrochloride liver damage with the use of the complex herbal product on the 7 th day of the experiment $(M+0, n=8)$.

\begin{tabular}{|c|c|c|c|c|c|c|c|}
\hline \multirow[b]{2}{*}{ No. } & \multirow[b]{2}{*}{$\begin{array}{c}\text { Biochemical } \\
\text { indicators }\end{array}$} & \multirow[b]{2}{*}{$\begin{array}{l}\text { Intact } \\
\text { rats }\end{array}$} & \multicolumn{5}{|c|}{ Experimental groups of animals (D-Galactosamine hepatitis) } \\
\hline & & & $\begin{array}{c}\text { Control }+ \\
\mathrm{H} 2 \mathrm{O}\end{array}$ & $\begin{array}{c}\text { Experimen- } \\
\text { tal group }+ \\
\text { Carsil }\end{array}$ & $\begin{array}{c}\text { Group } 1+100 \\
\text { mg/kg CHP }\end{array}$ & $\begin{array}{c}\text { Group } 2+200 \\
\text { mg/kg CHP }\end{array}$ & $\begin{array}{c}\text { Group } 3+300 \\
\text { mg/kg CHP }\end{array}$ \\
\hline 1 & Fibrinogen, g/L & $2.43 \pm 0.13$ & $1.51 \pm 0.11^{* 1}$ & $1.67 \pm 0.18$ & $1.92 \pm 0.13^{* 2}$ & $1.97 \pm 0.12^{* 2}$ & $1.99 \pm 0.11^{* 2}$ \\
\hline 2 & APTT, sec & $23.04 \pm 1.9$ & $34.24 \pm 1.7^{* 1}$ & $31.4 \pm 1.53$ & $28.9 \pm 1.4^{* 2}$ & $28.2 \pm 1.3^{* 2}$ & $27.89 \pm 1.25^{* 2}$ \\
\hline 3 & PI, \% & $84.4 \pm 4.7$ & $51.3 \pm 2.4^{* 1}$ & $56.3 \pm 3.7$ & $62.1 \pm 3.16^{* 2}$ & $61.9 \pm 2.8^{* 2}$ & $60.8 \pm 3.2^{* 2}$ \\
\hline 4 & PT, sec & $19.5 \pm 1.6$ & $33.7 \pm 1.7^{* 1}$ & $27.8 \pm 1.9$ & $26.8 \pm 1.9^{* 2}$ & $25.9 \pm 1.7^{* 2}$ & $26.3 \pm 2.1^{* 2}$ \\
\hline 5 & INR, RU & $1.22 \pm 0.12$ & $2.93 \pm 0.14^{* 1}$ & $2.57 \pm 0.18$ * & $2.34 \pm 0.17^{* 2}$ & $2.32 \pm 0.19 * 2$ & $2.16 \pm 0.17^{* 2}$ \\
\hline 6 & PR, \% & $1.16 \pm 0.12$ & $2.53 \pm 0.17^{* 1}$ & $2.17 \pm 0.19$ & $2.05 \pm 0.11^{2}$ & $2.02 \pm 0.13^{* 2}$ & $2.04 \pm 0.11^{* 2}$ \\
\hline
\end{tabular}


The prothrombin time (PT) indicator makes it possible to quickly assess not only the external hemostasis system, but also the entire blood coagulation reactions cascade. The PT indicator significantly increased in D-Galactosamine liver damage in white rats, with significant differences from the intact group remaining on the 14th day of the experiment (Table 2). On the 7th day of the experiment, half of animals of the experimental group receiving Carsil showed a tendency to increase PT. With the use of CHP at doses of $100 \mathrm{mg} /$ $\mathrm{kg}, 200 \mathrm{mg} / \mathrm{kg}, 300 \mathrm{mg} / \mathrm{kg}$, a significant decrease in PT was observed in groups of animals with acute hepatitis compared to the control group (21-23\%) on the 7th day of the experiment.

In D-Galactosamine hepatitis, prothrombin ratio (PR) being the integral part of the study of prothrombin blood complex increased significantly in the group of control animals. Against the background of the introduction of Carsil to white rats, there was a decrease in PR compared to the control group in 2 animals out of 8 , and an average decrease was $14.2 \%$. The use of the studied polyextract in white rats significantly reduced PR and hypocoagulation manifestation in comparison with the control group: it was revealed in 6 animals out of 8 .

To assess the state of prothrombin complex in case of liver damage by D-Galactosamine, the indicator of the international normalized ratio (INR) was used, which confirmed the development of significant hypocoagulation disorders in the control group of animals. In the experimental group, after the introduction of Carsil to white rats, the difference by $12 \%$ between this group and the control one was noted in the given period. When using the studied herbal product at doses of 100 $\mathrm{mg} / \mathrm{kg}, 200 \mathrm{mg} / \mathrm{kg}, 300 \mathrm{mg} / \mathrm{kg}$ in groups of animals in the early stages of the experiment, the difference of INR between this group and the control one amounted to $20 \%$ and more.

Table 2

Status of blood coagulation cascade in white rats in the case of D-Galactosamine hydrochloride liver damage with the introduction of the complex herbal product on the 14th day of the experiment $(M+0, n=8)$.

\begin{tabular}{|c|c|c|c|c|c|c|c|}
\hline & & \multicolumn{5}{|c|}{ Experimental groups of animals (D-Galactosamine hepatitis) } \\
\hline No. & $\begin{array}{c}\text { Biochemical } \\
\text { indicators }\end{array}$ & Intact rats & $\begin{array}{c}\text { Control + } \\
\text { H2O }\end{array}$ & $\begin{array}{c}\text { Experimen- } \\
\text { tal group } \\
\text { Carsil }\end{array}$ & $\begin{array}{c}\text { Group 1 } \\
\text { CHP 100 mg/ } \\
\text { kg }\end{array}$ & $\begin{array}{c}\text { Group 2 } \\
\text { CHP 200 mg/ } \\
\text { kg }\end{array}$ & $\begin{array}{c}\text { Group 3 + } \\
\text { CHP 300 mg/ } \\
\text { kg }\end{array}$ \\
\hline 1 & $\begin{array}{c}\text { Fibrinogen, } \\
\text { g/L }\end{array}$ & $2.43 \pm 0.13$ & $1.64 \pm 0.11^{* 1}$ & $1.85 \pm 0.19$ & $2.01 \pm 0.10^{* 2}$ & $2.04 \pm 0.12^{* 2}$ & $1.99 \pm 0.11^{* 2}$ \\
\hline 2 & APTT, sec & $23.04 \pm 1.9$ & $29.7 \pm 2.1^{* 1}$ & $25.7 \pm 1.9$ & $23.5 \pm 1.17^{* 2}$ & $23.4 \pm 1.21^{* 2}$ & $23.3 \pm 1.11^{2}$ \\
\hline 3 & PI, \% & $84.4 \pm 4.7$ & $62.1 \pm 3.4^{* 1}$ & $75.4 \pm 6.4$ & $79.5 \pm 3.9^{* 2}$ & $80.7 \pm 6.2^{* 2}$ & $79.8 \pm 5.7^{* 2}$ \\
\hline 4 & PT, sec & $19.9 \pm 1.6$ & $25.9 \pm 1.2^{* 1}$ & $23.2 \pm 1.7$ & $21.83 \pm 1.1^{* 2}$ & $21.6 \pm 1.3^{* 2}$ & $21.46 \pm 1.2^{* 2}$ \\
\hline 5 & INR, RU & $1.22 \pm 0.12$ & $2.13 \pm 0.15^{* 1}$ & $1.97 \pm 0.19$ & $1.58 \pm 0.12^{*}$ & $1.62 \pm 0.14^{* 2}$ & $1.57 \pm 0.15^{* 2}$ \\
\hline 6 & PR, \% & $1.16 \pm 0.12$ & $1.87 \pm 0.11^{* 1}$ & $1.48 \pm 0.13$ & $1.41 \pm 0.12^{*}$ & $1.38 \pm 0.13^{* 2}$ & $1.37 \pm 0.10^{* 2}$ \\
\hline
\end{tabular}

On the 14th day of the experiment, in the control group of animals in the case of D-Galactosamine liver damage, significant differences in indicators showing the violations of the coagulogram remained (Table 2). With the introduction of Carsil, there was a tendency towards an increase in prothrombin index, fibrinogen, and APTT in animals, but no reliable values were revealed in this group.

In the second week of the examination, the content of fibrinogenincreased by $27-30 \%$ compared to the control group with the introduction of the studied polyextract at doses of $100 \mathrm{mg} / \mathrm{kg}$, $200 \mathrm{mg} /$ $\mathrm{kg}, 300 \mathrm{mg} / \mathrm{kg}$ in white rats. The use of the CHP contributed to the increase in prothrombin index (Table 2) by $25-27 \%$ compared to the control. In the second week of the experiment, the level of APTT decreased by $21.5 \%$ and approached the level of the intact group in most animals. At the same time, the PR and INR indicators significantly decreased, confirming the decrease of hypocoagulation disorders in the group of animals receiving the CHP.

\section{Conclusion}

Experimental hepatitis caused by the introduction of D-Galactosamine hydrochloride was characterized by the development of hypocoagulation disorders associated with a decrease in the fibrinogen level, prothrombin complex factors due to the violations of the synthesizing function of hepatocytes. The dynamics of additional indicators of coagulogram, APTT, PI, PR, and INR confirmed the coagulation disorders.

In the severe course of the pathological process in the liver, the possibility of the development of 
the disseminated intravascular coagulation (DIC) having a general biological orientation and capable of becoming cascading is of particular significance. DIC, as is known, can proceed not only in the pronounced clinical form, but also in the form of compensated or subcompensated process, significantly burden the course of the pathological process. The hypocoagulation disorders detected in the experimental animals correspond to the second phase of DIC syndrome.

Hemostasis disorders in D-Galactosamine hydrochloride liver damage can be caused by a combination of the insufficient synthetic function of hepatocytes in formation of coagulation factors and the possibility of development of DIC syndrome. Determination of coagulation disorders testifies to the diagnostic value of these deviations in the assessment of severity, probable prognosis, and need for correction in case of liver damage.

When using the Carsil reference hepatoprotector in a group of experimental animals with D-Galactosamine hepatitis, there is a clear tendency to decrease in the manifestations of coagulation disorders, but no significant differences were noted. The introduction of the CHP led to the significant reduction of hypocoagulation, moreover, from the early stages of the experiment, but no distinct dosedependent effect was revealed.

Conflict of interest. The authors declare that there is no conflict of interest.

\section{References:}

1. Infectious Diseases. National guidance. Ed. N.D. Ushchuk, Yu.Ya. Vengerov. M., 2010: 1056.

2. Sherlok Sh., Duli D. Diseases of the Liver and Biliary Tracts. Ed. Z.G. Aprosina, N.A. Mukhin. M., 2002: 864 .

3. Nikonov G.K., Manujlov B.M. Fundamentals of Modern Phytotherapy. M., 2005: 520.

4. Nikolaev S.M. Phytopharmaco-therapy and Phytopharmaco-prevention of Diseases. Ulan-Ude, 2012: 286.
5. Lesiovskaya E.E. Scientific Phytotherapy. M., 2014.

6. Barkagan Z.S., Momot A.P. Fundamentals of Diagnostics of Hemostasis Disorders. M., 1999: 290.

7. Guidance on Experimental (Preclinical) Study of New Pharmaceutical Substances. Ed. R.U. Khabriev. M., 2012: 832.

\section{Contacts}

Corresponding author: Ubeeva Elena Aleksandrovna, Postgraduate student of the Department of Pharmacology, Buryat State University, Ulan-Ude.

670002, Ulan-Ude, ul. Oktyabrskaya, 36a.

Tel.: 8 (9021) 612296.

E-mail: ubeeva.ip@mail.ru

\section{Author information}

Nikolaev Sergei Matveevich, Doctor of Medical Sciences, Professor of the Department of Pharmacology and Traditional Medicine, Buryat State University, Senior Research Scientist of IGEB SB RAS, Ulan-Ude.

670002, Ulan-Ude, ul. Oktyabrskaya, 36a.

Tel.: (3012) 297170.

E-mail: univer@bsu.ru

Olennikov Daniil Nikolaevich, Doctor of Biological Sciences, Senior Researcher of IGEB SB RAS, UlanUde.

670047, Ulan-Ude, ul. Sakhyanovoi, 6.

Tel.: 8 (9021) 600627.

E-mail: olennikovdn@mail.ru

Ubeeva Iraida Polikarpovna, Doctor of Medical Sciences, Professor of the Department of Infectious Diseases, Buryat State University, Ulan-Ude.

670002, Ulan-Ude, ul. Oktyabrskaya, 36a.

Tel.: (3012) 297170.

E-mail: univer@bsu.ru 